Article

\title{
Substantial LIB Anode Performance of Graphitic Carbon Nanoflakes Derived from Biomass Green-Tea Waste
}

\author{
Sankar Sekar ${ }^{1,2}$, Youngmin Lee ${ }^{1,2}$, Deuk Young Kim ${ }^{1,2}$ and Sejoon Lee ${ }^{1,2, * \mathbb{C}}$ \\ 1 Department of Semiconductor Science, Dongguk University-Seoul, Seoul 04620, Korea; \\ sanssekar@gmail.com (S.S.); ymlee@dongguk.edu (Y.L.); dykim@dongguk.edu (D.Y.K.) \\ 2 Quantum-functional Semiconductor Research Center, Dongguk University-Seoul, Seoul 04620, Korea \\ * Correspondence: sejoon@dongguk.edu; Tel.: +82-2-2260-3946; Fax: +82-2-2260-3945
}

Received: 16 May 2019; Accepted: 5 June 2019; Published: 7 June 2019

\begin{abstract}
Biomass-derived carbonaceous constituents constitute fascinating green technology for electrochemical energy-storage devices. In light of this, interconnected mesoporous graphitic carbon nanoflakes were synthesized by utilizing waste green-tea powders through the sequential steps of air-assisted carbonization, followed by potassium hydroxide activation and water treatment. Green-tea waste-derived graphitic carbon displays an interconnected network of aggregated mesoporous nanoflakes. When using the mesoporous graphitic carbon nanoflakes as an anode material for the lithium-ion battery, an initial capacity of $\sim 706 \mathrm{mAh} / \mathrm{g}$ and a reversible discharge capacity of $\sim 400 \mathrm{mAh} / \mathrm{g}$ are achieved. Furthermore, the device sustains a large coulombic efficiency up to $96 \%$ during 100 operation cycles under the applied current density of $0.1 \mathrm{~A} / \mathrm{g}$. These findings depict that the bio-generated mesoporous graphitic carbon nanoflakes could be effectively utilized as a high-quality anode material in lithium-ion battery devices.
\end{abstract}

Keywords: biomass; mesoporous graphitic carbon; anode; lithium-ion battery

\section{Introduction}

A continuous global demand for green energy technology encouraged tremendous efforts toward the evolution of renewable and environmentally friendly devices that can effectively convert and store efficient energy sources [1,2]. Among various energy devices, lithium-ion batteries (LIBs) are regarded as next-generation mobile electrical-energy-storage modules because of their high energy capacity and the excellent cyclic durability. The electrochemical performances of LIBs strongly rely on the choice of the electrode material; hence, exploiting a high-quality electrode source material is necessary to improve the energy-storage capacity of LIBs [3-5]. To date, several types of electrode materials (e.g., conductive polymers, transition metal oxides, carbonaceous materials, hydroxides, etc.) were investigated and proposed as feasible anode sources for LIBs [6-11]. Compared to other materials, carbonaceous constituents (e.g., activated carbon, carbon nanotubes, graphitic carbon, graphene, graphite, etc.) could become suitable candidates because of their high safety, high electrical conductivity, low cost, excellent electrochemical stability, high mechanical robustness, and outstanding electrolyte-ion accessibility [12-14]. In particular, porous graphitic carbon nanostructures emerged as a powerful candidate because they can provide a small diffusion pathway for ion transport, as well as a large active area for the electrochemical reaction $[15,16]$. In addition, biomass-derived porous graphitic carbon nanostructures are of ample interest due to their cost effectiveness, environmental friendliness, vast abundance, and fast regeneration. According to previous literature, it was reported that the biomass graphitic carbon nanostructures could be derived and synthesized from various 
natural resources such as cellulose [17], sucrose [18], natural cotton [19], garlic peel [20], wheat flour [21], Sterculia scaphigera [22], wheat stalk [23], and waste tea powders [24-26]. Among them, the green-tea waste is a cheap and abundant biomass source. The amount of world green-tea production in 2015 was 1.8 billion kilograms for consumption [25], and the green-tea waste contains 3.5-7\% inorganic components, as well as $93.0-96.5 \%$ organic components $[27,28]$. In this regard, recently, we derived high-quality graphitic carbon nanoflakes from green-tea waste, and used them as an electrode source material for a high-performance supercapacitor [26]. Despite such great potential of green-tea-derived biomass graphitic carbon, its electrochemical performance as an LIB anode was rarely investigated except for a few previous studies [24,25].

Motivated by all the above, we derived the interconnected mesoporous graphitic carbon (IMP-GC) nanoflakes from waste green-tea powders, and characterized their astonishing material properties as an LIB anode material. The IMP-GC nanoflakes were synthesized via the following procedures of eco-friendly simple steps: air-assisted carbonization, followed by potassium hydroxide (KOH) activation and water treatment. The structural, microstructural, textural, and electrochemical characteristics of the synthesized IMP-GC nanoflakes were thoroughly examined in detail.

\section{Experimental Details}

\subsection{IMP-GC Nanoflake Synthesis}

Figure 1 shows the experimental schemes for the derivation and the synthesis of the IMP-GC nanoflakes using waste green-tea powders through air-assisted carbonization, $\mathrm{KOH}$ activation, and water treatment. For this process, we used the waste green-tea powders (from green-tea bags) as a biomass carbonaceous resource. Firstly, the raw materials of the waste green-tea powders were transferred into the alumina crucible, and were carbonized in air at $500{ }^{\circ} \mathrm{C}$ for 60 min to accumulate their residues (i.e., green-tea ashes (GTAs)). Then, GTAs were mixed with $\mathrm{KOH}$ at a molar ratio of $\mathrm{GTA} / \mathrm{KOH}=1 / 4$, and the GTA-KOH mixtures were activated in air at $600{ }^{\circ} \mathrm{C}$ for $120 \mathrm{~min}$. Thereafter, the $\mathrm{KOH}$-activated GTA products were treated with water by blending them in deionized water for $6 \mathrm{~h}$. Here, the water treatment was aimed at enhancing the graphitization rate of the IMP-GC nanoflakes [26]. After filtering out the precipitates of potassium compounds, the obtained graphitic carbon products were cleaned again by deionized water, and were dried at $150{ }^{\circ} \mathrm{C}$ for $8 \mathrm{~h}$ in vacuum.
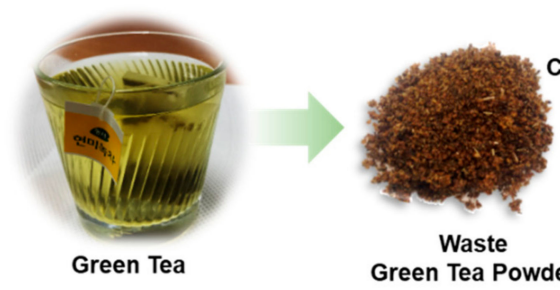

Green Tea Powder

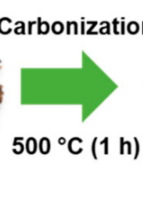
(GTA)
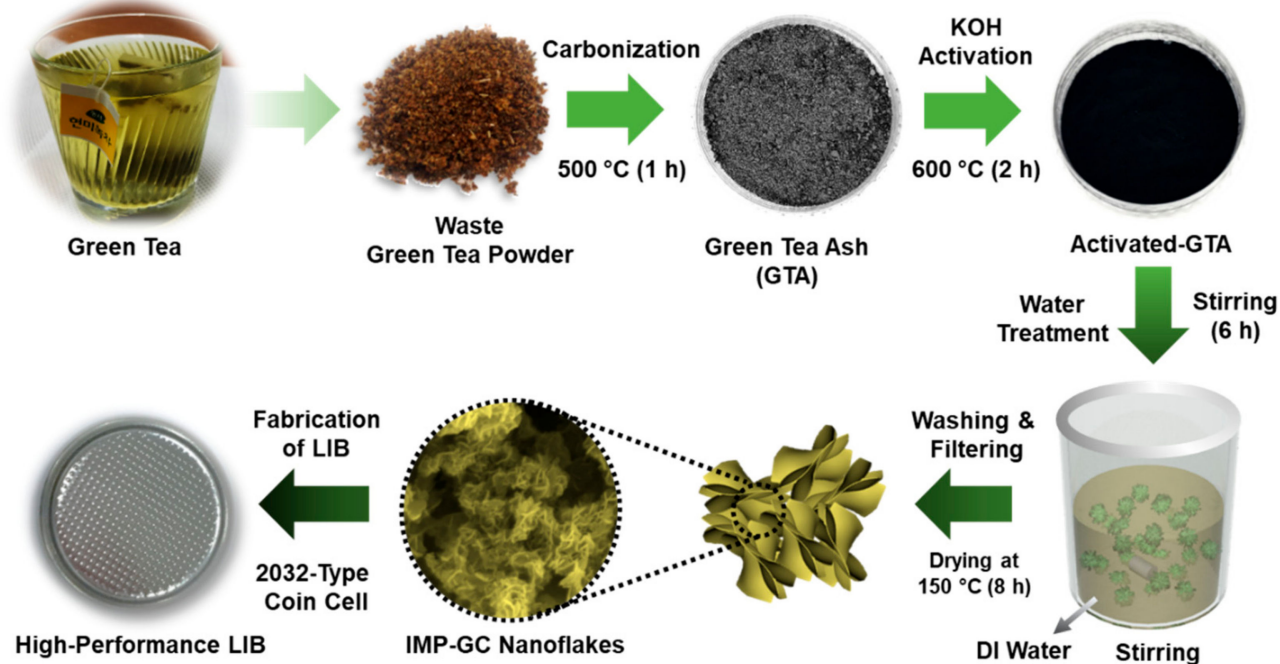

Figure 1. Schematic illustration of the synthesis procedures for the preparation of interconnected mesoporous graphitic carbon (IMP-GC) nanoflakes using a biomass carbonaceous resource derived from green-tea waste via potassium hydroxide $(\mathrm{KOH})$ activation. 


\subsection{Measurements of Material Characteristics}

The crystallographic structure of IMP-GC was characterized through X-ray diffraction (XRD), and the graphitic nature of IMP-GC was analyzed by Raman scattering spectroscopy under green laser excitation $(\lambda=532 \mathrm{~nm}$ ). The morphology and the microstructure of IMP-GC were monitored by scanning electron microscopy (SEM, Phillips, Eindhoven, The Netherlands) and transmission electron microscopy (TEM, JEOL USA Inc., Peabody, MA, USA), respectively. The textural pore characteristics were evaluated by nitrogen adsorption-desorption isotherm measurements at $77 \mathrm{~K}$.

\subsection{Electrochemical Performance Measurements}

The LIB performances (i.e., electrochemical properties of IMP-GC as an LIB anodic source) were assessed using a 2032-type coin cell. The anodic source of LIB was prepared by blending the IMP-GC nanoflakes (80\%) in an $N$-methyl-2-pyrrolidinone solution. We here note that $10 \%$ polyvinylidene difluoride and $10 \%$ carbon black were also incorporated as additives for increasing the network conductivity of the IMP-GC nanoflakes. The prepared anodic source was then painted onto the current collector part (i.e., copper foil). After subsequent curing at $80^{\circ} \mathrm{C}$ for $10 \mathrm{~h}$, the electrode was assembled in an LIB coin cell under Ar atmosphere. The mass of the loaded electrode source material was $\sim 0.82 \mathrm{mg}$. Here, the separator and the counter electrode were configured with a Celgard trilayer (PP/PE/PP) and a lithium foil, respectively. In addition, the electrolyte was composed of an $\mathrm{LiPF}_{6}$ solution (1 M) with a combination of dimethyl carbonate and ethylene carbonate (1:1). The cyclic voltammetry $(\mathrm{CV})$ properties of the fabricated LIB device were examined at a scan rate $\left(\mathrm{r}_{\mathrm{sc}}\right)$ of $1 \mathrm{mV} / \mathrm{s}$ within the potential range of $0.01-3.0 \mathrm{~V}$ (vs. $\mathrm{Li} / \mathrm{Li}^{+}$). The galvanostatic charge-discharge $(\mathrm{GCD})$ characteristics were analyzed at $0.01-3.0 \mathrm{~V}$ by injecting the applied current $\left(\mathrm{J}_{\mathrm{a}}\right)$ of $100 \mathrm{~mA} / \mathrm{g}$. The electrochemical impedance spectrometry (EIS) measurements were conducted at frequencies of $0.01-100 \mathrm{kHz}$.

\section{Results and Discussion}

GTA-derived IMP-GC displays no distinct diffraction patterns except for (002) and (100) phases (Figure 2a). The broad peak at $\sim 22^{\circ}$ is a typical XRD pattern from the $(002)$ crystallized carbon phase, and is indicative of the layered structure of multiple graphene sheets. The small peak of the (100) phase at $\sim 44^{\circ}$ arises from $s p^{2}$-hybridized carbon with a honeycomb structure $[9,29,30]$. This represents that our IMP-GC nanoflakes possess a graphitic structure of carbon materials. The precise features of the IMP-GC nanoflakes can be further elucidated from their Raman scattering characteristics (Figure 2b). The sample exhibits three predominant peaks from D, G, and 2D bands, originating from the local vibration of disordered/defective features of graphite structures, the $\mathrm{E}_{2 \mathrm{~g}}$ vibration mode in $s p^{2}$-hybridized carbon, and the stacking of graphene sheets (i.e., signature of graphitic carbon), respectively [31,32]. Here, it is worth noting that the intensity ratio of $\mathrm{D}$ to $\mathrm{G}$ (i.e., $\mathrm{I}_{\mathrm{D}} / \mathrm{I}_{\mathrm{G}}$ ) is $\sim 0.93$. Since the magnitude of $\mathrm{I}_{\mathrm{D}} / \mathrm{I}_{\mathrm{G}}$ depicts a degree of graphitization in carbonaceous materials [33], one can conjecture that the biomass GTA-derived IMP-GC nanoflakes are highly graphitized. The total mass loss of the air-assisted green-tea powders (Figure S1, Supplementary Materials) is around 24.2\%, demonstrating the high thermal stability of the materials [34].

The textural properties of IMP-GC were evaluated by the nitrogen adsorption-desorption isotherm measurements at $77 \mathrm{~K}$. The IMP-GC nanoflakes reveal an isotherm characteristic of type I/IV adsorption-desorption with a type $\mathrm{H} 4$ hysteresis loop (Figure 2c), associated with both mesoporous and microporous structures [35,36]. Through the Brunauer-Emmett-Teller method, it was confirmed that the IMP-GC nanoflakes have a relatively large specific surface area $\left(\sim 1373 \mathrm{~m}^{2} / \mathrm{g}\right)$ and a great total pore volume $\left(\sim 0.4093 \mathrm{~cm}^{3} / \mathrm{g}\right)$. These are much greater than those of other green-tea-derived graphitic carbon nanostructures [24-26]. Figure 2d displays the pore characteristics of the IMP-GC nanoflakes. By means of the Barrett-Joyner-Halenda analysis, the average pore size and the pore surface area of the IMP-GC nanoflakes were calculated to be $\sim 1.62 \mathrm{~nm}$ and $\sim 479.52 \mathrm{~m}^{2} / \mathrm{g}$, respectively. The microporous nature of the IMP-GC nanoflakes was also confirmed from the $t$-plot analysis 
(see Figure S1, Supplementary Materials). Specifically, the micropore volume and size of the IMP-GC nanoflakes were measured to be $\sim 0.5066 \mathrm{~cm}^{3} / \mathrm{g}$ and $\sim 0.72 \mathrm{~nm}$, respectively, from the t-plot analysis. These specify that the IMP-GC nanoflakes are constructed with a micro/mesoporous structure. Both the large surface area and the micro/mesoporous structure render an electrolyte-electrode interfacial area huge enough to accumulate abundant charges and ions; hence, the electrochemical performances of IMP-GC as an LIB anode could be enhanced, as explained in detail later.
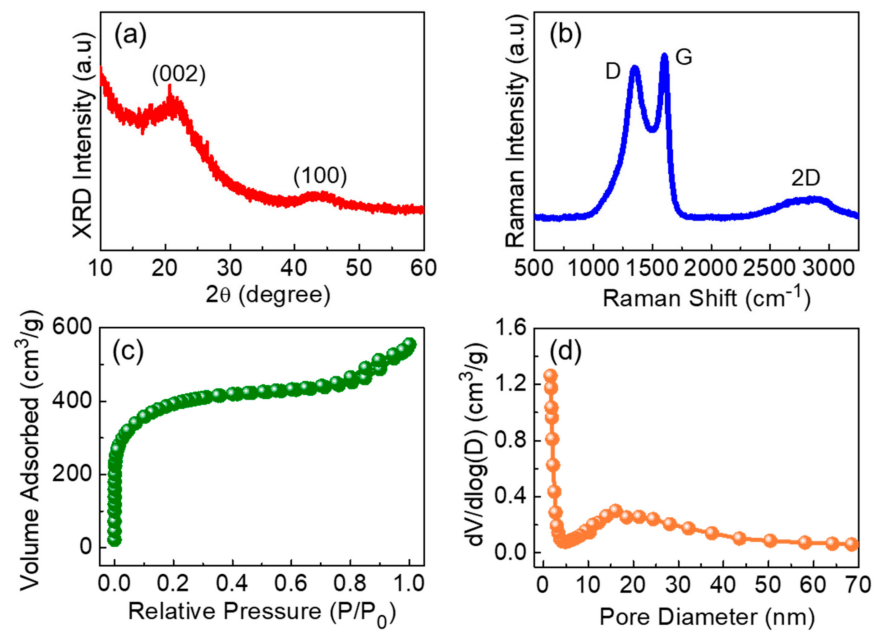

Figure 2. (a) X-ray diffraction (XRD) pattern, (b) Raman spectrum, (c) $\mathrm{N}_{2}$ adsorption-desorption isotherm characteristics, and (d) pore size distribution of the IMP-GC nanoflakes derived from waste green tea.

Figure 3a,b show the SEM images of the GTA-derived IMP-GC nanoflakes. The sample exhibits an interconnected network of the mesoporous GC nanoflakes with a width of about 6-10 nm. When the annealing temperature was increased from 600 to $900{ }^{\circ} \mathrm{C}$, the samples showed an aggregated flake structure (see Figure S3, Supplementary Materials). The microstructure of the IMP-GC nanoflakes was further elucidated by TEM. As displayed in Figure 3c, the IMP-GC nanoflakes are composed of highly interconnected mesoporous activated carbon nanoflakes. From the in situ energy-dispersive $X$-ray (EDX) measurement, the IMP-GC nanoflakes were ratified to consist of a major component of $C$ (inset of Figure 3c). Small amounts of $\mathrm{Cu}$ and $\mathrm{O}$ are thought to arise from the TEM grid. The selective-area electron diffraction patterns (i.e., ring patterns) pronounce that the IMP-GC nanoflakes are well graphitized, as confirmed from the XRD and Raman analyses.
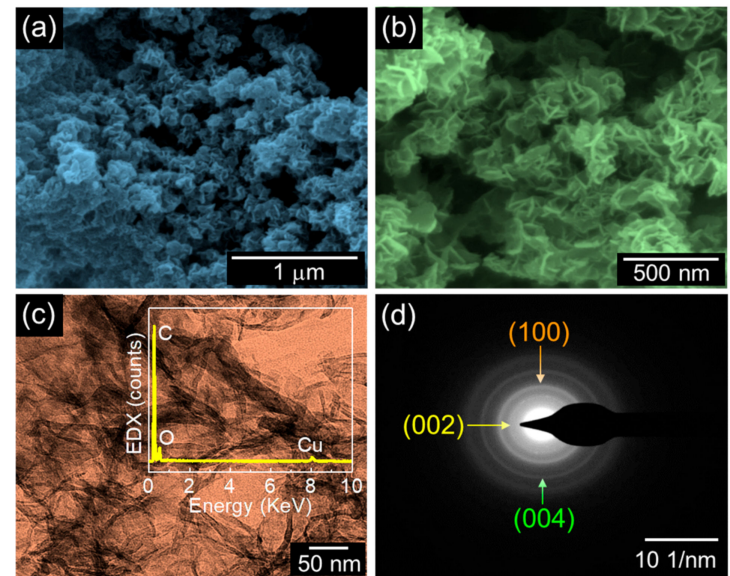

Figure 3. Morphological, microstructural, and compositional properties of the IMP-GC nanoflakes: (a) field-emission (FE)-SEM image; (b) zoomed-in FE-SEM image; (c) high-resolution TEM image with the in situ energy-dispersive X-ray (EDX) spectrum (inset); (d) selective-area electron diffraction pattern. 
After confirming the effective synthesis of biomass IMP-GC nanoflakes using green-tea waste, we assessed their electrochemical characteristics as an LIB anode material. Figure 4a displays the CV curves of the fabricated LIB sample measured under $r_{\mathrm{sc}}=0.1 \mathrm{mV} / \mathrm{s}$ within $0-3.0 \mathrm{~V}\left(\mathrm{vs}\right.$. Li/ $\left.\mathrm{Li}^{+}\right)$. The first cyclic CV curve shows a wide reduction in the cathodic region, which is indicative of both the formation of the solid electrolyte interface (SEI) layer onto the IMP-GC surface and the decomposition of the electrolyte [37-39]. Such a wide reduction disappears during consecutive cycles, while the CV curves maintain an almost identical area during all subsequent cycles. This represents the high stability of the IMP-GC structure. Figure $4 \mathrm{~b}$ represents the first, second, 50th, and 100th GCD profiles measured at constant Ja of $0.1 \mathrm{~A} / \mathrm{g}$. Due to both the SEI formation and the other-side reaction $[37,40,41]$, the LIB device reveals two plateaus at $\sim 0.5$ and $\sim 0.75 \mathrm{~V}$ during the first discharge cycle. In subsequent cycles, these two plateaus disappear because of the high stability of IMP-GC. The initial charge and discharge capacity values reach $\sim 455$ and $\sim 706 \mathrm{mAh} / \mathrm{g}$, respectively. Accordingly, the initial coulombic efficiency of the IMP-GC electrode is $\sim 64.4 \%$. The high irreversible capacity is observable for the first GCD cycle because of the irreversible $\mathrm{Li}^{+}$intercalation into the particular IMP-GC position and/or the creation of the SEI layer [42,43]. Since the SEI layer suppresses the electrolyte decomposition on the carbon electrode, the shapes of the GCD profiles become distinctive again and again for the following cycles. In addition, the reversible capacities are stabilized while the irreversible capacities disappear. From the GCD profiles, it was also confirmed that the discharge capacity of IMP-GC is comparable to and even higher than that of other biomass graphitic and activated carbon nanostructures [20-25,43-51] (see Table 1).
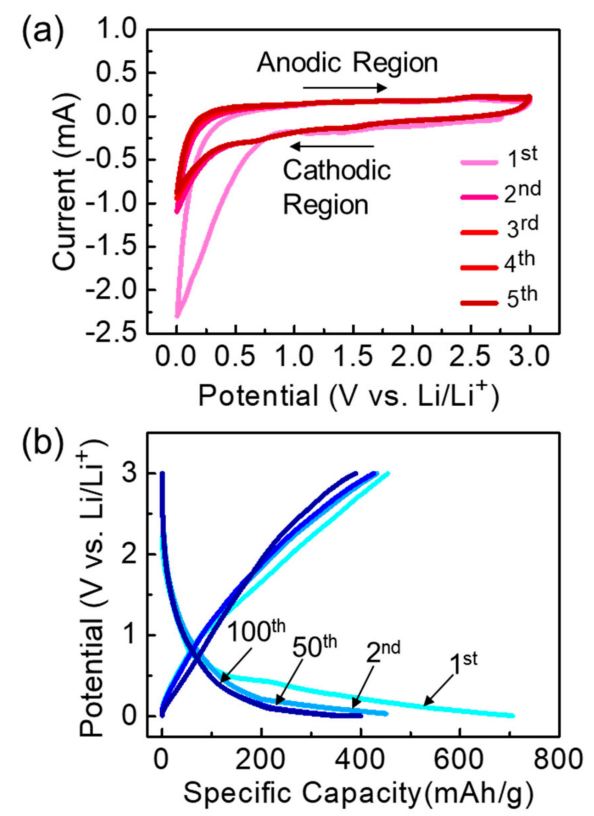

Figure 4. (a) Cyclic voltammetry (CV) curves measured under $\mathrm{r}_{\mathrm{sc}}$ of $0.1 \mathrm{mV} / \mathrm{s}$, and (b) galvanostatic charge-discharge (GCD) curves measured under $\mathrm{J}_{\mathrm{a}}$ of $0.1 \mathrm{~A} / \mathrm{g}$ for the lithium ion battery (LIB) device with the anode material of IMP-GC nanoflakes. 
Table 1. Comparison of electrochemical performances for various biomass-derived carbon nanostructures used as lithium ion battery (LIB) anode materials.

\begin{tabular}{ccccc}
\hline Biomass Resource & Measurement Condition & $\begin{array}{c}\text { Initial Capacity } \\
\text { (mAh/g) }\end{array}$ & $\begin{array}{c}\text { Capacity Retention } \\
\text { (mAh/g) }\end{array}$ & Reference \\
\hline Waste green tea & $0.1 \mathrm{~A} / \mathrm{g}$ & 706 & 400 at $0.1 \mathrm{~A} / \mathrm{g}$ after 100 cycles & This work \\
Garlic peel & $0.1 \mathrm{~A} / \mathrm{g}$ & 551 & 540 at $0.1 \mathrm{~A} / \mathrm{g}$ after 100 cycles & 20 \\
Wheat flour & $1 \mathrm{C}$ & 728 & 217 at $1 \mathrm{C}$ after 100 cycles & 21 \\
Sterculia scaphigera & $0.1 \mathrm{C}$ & 1539 & 423 at $0.1 \mathrm{C}$ after 100 cycles & 22 \\
Wheat stalk & $0.1 \mathrm{C}$ & 502 & $\sim 140$ at $10 \mathrm{C}$ after 3000 cycles & 23 \\
Green tea leave & $0.1 \mathrm{C}$ & 530 & $\sim 450$ at $0.1 \mathrm{C}$ after 50 cycles & 24 \\
Waste green tea & $0.1 \mathrm{C}$ & 869 & 479 at $0.2 \mathrm{C}$ after 200 cycles & 25 \\
Walnut shell & $0.1 \mathrm{~A} / \mathrm{g}$ & 150 & 150 at $0.1 \mathrm{~A} / \mathrm{g}$ after 100 cycles & 43 \\
Peanut shell & $1 \mathrm{~A} / \mathrm{g}$ & 761 & 314 at $1 \mathrm{~A} / \mathrm{g}$ after 400 cycles & 44 \\
Sugar & $0.1 \mathrm{~A} / \mathrm{g}$ & 477 & & - \\
Cherry stones & $0.1 \mathrm{C}$ & 790 & 210 at $0.1 \mathrm{C}$ after 100 cycles & 46 \\
Orange peel & $1 \mathrm{~A} / \mathrm{g}$ & 878 & 301 at $1 \mathrm{~A} / \mathrm{g}$ after 100 cycles & 47 \\
Petroleum coke & $0.1 \mathrm{C}$ & 320 & 293 at $0.1 \mathrm{C}$ after 300 cycles & 48 \\
Coffee waste & $0.1 \mathrm{~A} / \mathrm{g}$ & 359 & 262 at $0.1 \mathrm{~A} / \mathrm{g}$ after 100 cycles & 49 \\
Alginic acid & $0.7 \mathrm{C}$ & 420 & 80 at $45 \mathrm{C}$ after 1500 cycles & 50 \\
Olive stones & $0.2 \mathrm{C}$ & 615 & 170 at $0.2 \mathrm{C}$ after 100 cycles & 51 \\
\hline
\end{tabular}

Note: $1 \mathrm{C}=372 \mathrm{~mA} / \mathrm{g}$.

Next, we examined the rate capability of the LIB sample by changing Ja from 100 to $2000 \mathrm{~mA} / \mathrm{g}$. As can be seen from Figure 5a, the device exhibits the discharge capacities of 454, 352, 183, 125, and $90 \mathrm{mAh} / \mathrm{g}$ at $\mathrm{J}_{\mathrm{a}}$ of $0.1,0.2,0.5,1$, and $2 \mathrm{~A} / \mathrm{g}$, respectively. Owing to the high surface area of uniform pores in IMP-GC, more than $20 \%$ of the specific discharge capacity is retained even after applying high $\mathrm{J}_{\mathrm{a}}$ up to $2 \mathrm{~A} / \mathrm{g}$. When returning back to $\mathrm{J}_{\mathrm{a}}=0.1 \mathrm{~A} / \mathrm{g}$, the discharge capacity is dramatically recovered to the original value. This demonstrates the excellent reversibility of the IMP-GC electrode. In addition, the IMP-GC nanoflakes also exhibit a good cyclic performance as an LIB anode. During 100 cycles under $\mathrm{J}_{\mathrm{a}}=0.1 \mathrm{~A} / \mathrm{g}$, the device sustains its large coulombic efficiency up to $96 \%$ (Figure $5 \mathrm{~b}$ ). However, the discharge capacity was slightly decreased by $\sim 12 \%$ (i.e., from $\sim 454$ to $\sim 400 \mathrm{mAh} / \mathrm{g}$ ), presumably because of the SEI decomposition via continuous insertion and extraction of $\mathrm{Li}$ ions for multiple discharge-charge cycles [52].

In energy-storage devices, the charge transfer resistance $\left(R_{c t}\right)$ is one of the most key parameters that represent the interface property between the electrolyte and the electrode. To determine $R_{c t}$, we measured the EIS characteristics of the LIB device. Figure 6 displays the Nyquist plots of the sample measured before and after the cyclic process at $\mathrm{J}_{\mathrm{a}}=0.1 \mathrm{~A} / \mathrm{g}$. The Nyquist plots include two distinguishable features of a semicircle and a long tail. Since the former at a higher-frequency region and the latter at a lower-frequency region depict $\mathrm{R}_{\mathrm{ct}}$ and Warburg impedance $\left(\mathrm{W}_{\mathrm{o}}\right.$, i.e., degree of $\mathrm{Li}$ ion diffusion into the electrode) [23], respectively, one can extract the $R_{\mathrm{ct}}$ value by analyzing the equivalent circuit for the fabricated LIB device (inset of Figure 6). Before the cyclic process, the device revealed a relatively lower value of $R_{\mathrm{ct}} \sim 60 \Omega$; then, the magnitude of $\mathrm{R}_{\mathrm{ct}}$ was further decreased to $\sim 54 \Omega$ after the cyclic process because of the SEI formation. From all the above results, we can conclude that the biomass GTA-derived IMP-GC nanoflakes could effectively play a substantial role as an anodic source material for high-performance LIBs. 
(a)

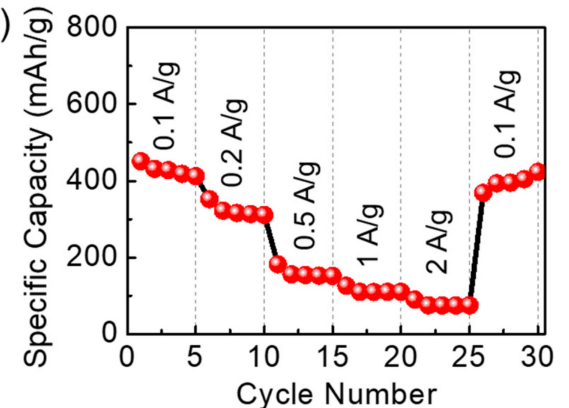

(b)

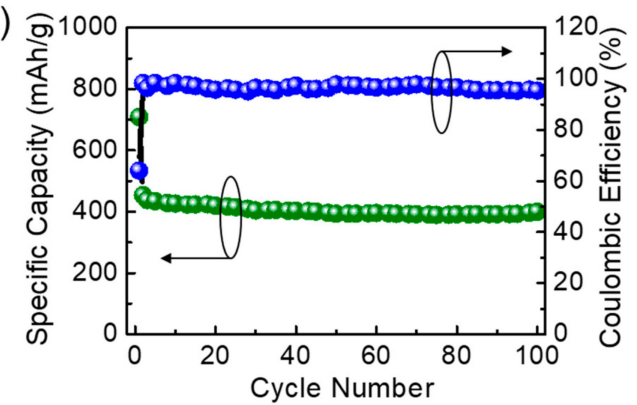

Figure 5. (a) Rate performance at various $\mathrm{J}_{\mathrm{a}}$, and (b) cyclic performance with its corresponding coulombic efficiency at $\mathrm{J}_{\mathrm{a}}$ of $0.1 \mathrm{~A} / \mathrm{g}$ for the LIB device with the anode material of IMP-GC nanoflakes.

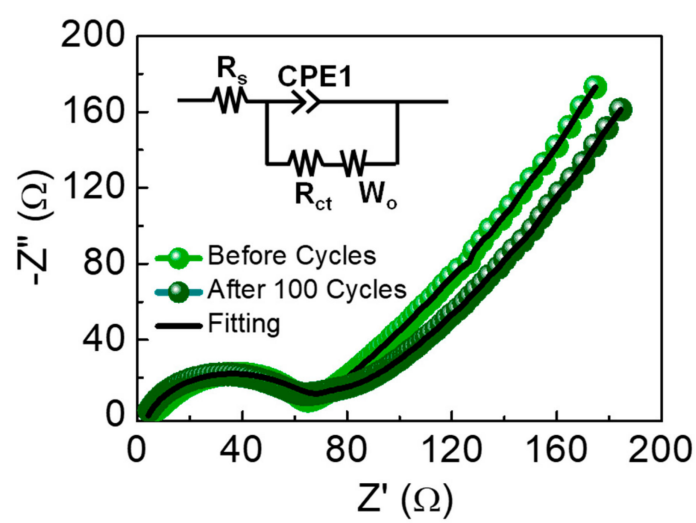

Figure 6. Nyquist plots before and after 100 charge-discharge cycles at $\mathrm{J}_{\mathrm{a}}=0.1 \mathrm{~A} / \mathrm{g}$ and the equivalent circuit (inset) for the LIB device with the anode material of IMP-GC nanoflakes.

\section{Conclusions}

The IMP-GC nanoflakes were successfully synthesized using biomass carbonaceous resources of GTAs that were obtained from waste green-tea powders. From the morphological and microstructural characteristics, the GTA-derived IMP-GC nanoflakes were confirmed to form an interconnected network of mesoporous nanoflakes having a vast specific surface area (i.e., $\sim 1373 \mathrm{~m}^{2} / \mathrm{g}$ ). The IMP-GC nanoflakes were also shown to play a substantial role as an LIB anode material. Specifically, the LIB device with the anode of IMP-GC nanoflakes revealed an outstanding rate performance (i.e., Li ion storage up to $\sim 400 \mathrm{mAh} / \mathrm{g}$ with a coulombic efficiency of $\sim 96 \%$ during 100 cycles under $\mathrm{J}_{\mathrm{a}}=0.1 \mathrm{~A} / \mathrm{g}$ ). Consequently, the biomass GTA-derived IMP-GC nanoflakes hold promise for low-cost green technology, particularly aimed at designing high-performance electrochemical energy-storage devices.

Supplementary Materials: The following are available online at http://www.mdpi.com/2079-4991/9/6/871/s1, Figure S1: Thermogravimetric analysis of the green tea powder ash; Figure S2: T-plot of the IMP-GC nanoflakes; Figure S3: Field-emission SEM images of the IMP-GC nanoflakes activated at (a) $700^{\circ} \mathrm{C}$, (b) $800{ }^{\circ} \mathrm{C}$, and (c) $900{ }^{\circ} \mathrm{C}$.

Author Contributions: Investigation and writing-original draft, S.S.; data curation, Y.L.; conceptualization, D.Y.K.; supervision and writing-review and editing, S.L. 
Funding: This research was supported by the National Research Foundation of Korea through the Basic Science Research Program (2016R1A6A1A03012877 and 2017R1A2B4004281) funded by the Korean government of the Ministry of Education.

Conflicts of Interest: The authors declare no conflicts of interest.

\section{References}

1. Poudel, P.; Qiao, Q. Carbon nanostructure counter electrodes for low cost and stable dye-sensitized solar cells. Nano Energy 2014, 4, 157-175. [CrossRef]

2. Abbasi, T.; Abbasi, S.A. Decarbonization of fossil fuels as a strategy to control global warming. Renew. Sustain. Energy Rev. 2011, 15, 1828-1834. [CrossRef]

3. Wang, G.; Zhang, L.; Zhang, J. A review of electrode materials for electrochemical supercapacitors. Chem. Soc. Rev. 2012, 41, 797-828. [CrossRef] [PubMed]

4. Wang, K.-X.; Li, X.-H.; Chen, J.-S. Surface and interface engineering of electrode materials for lithium-ion batteries. Adv. Mater. 2015, 27, 527-545. [CrossRef] [PubMed]

5. Pazhamalai, P.; Krishnamoorthy, K.; Sahoo, S.; Mariappan, V.K.; Kim, S.J. Copper tungsten sulfide anchored on Ni-foam as a high-performance binder free negative electrode for asymmetric supercapacitor. Chem. Eng. J. 2019, 359, 409-418. [CrossRef]

6. Mondal, A.K.; Su, D.; Wang, Y.; Chen, S.; Wang, G. Hydrothermal synthesis of nickel oxide nanosheets for lithium-ion batteries and supercapacitors with excellent performance. Chem. Asian J. 2013, 8, 2828-2832. [CrossRef] [PubMed]

7. Boukhalfa, S.; Evanoff, K.; Yushin, G. Atomic layer deposition of vanadium oxide on carbon nanotubes for high-power supercapacitor electrodes. Energy Environ. Sci. 2012, 5, 6872-6879. [CrossRef]

8. Yang, C.; Wei, H.; Guan, L.; Guo, J.; Wang, Y.; Yan, X.; Zhang, X.; Wei, S.; Guo, Z. Polymer nanocomposites for energy storage, energy saving, and anticorrosion. J. Mater. Chem. A 2015, 3, 14929-14941. [CrossRef]

9. Ru, H.; Xiang, K.; Zhou, W.; Zhu, Y.; Zhao, X.S.; Chen, H. Bean-dreg-derived carbon materials used as superior anode material for lithium-ion batteries. Electrochim. Acta 2016, 222, 551-560. [CrossRef]

10. Wang, B.; Wang, Y.; Peng, Y.; Wang, X.; Wang, N.; Wang, J.; Zhao, J. Nitrogen-doped biomass-based hierarchical porous carbon with large mesoporous volume for application in energy storage. Chem. Eng. J. 2018, 348, 850-859. [CrossRef]

11. Talapaneni, S.N.; Lee, J.H.; Je, S.H.; Buyukcakir, O.; Kwon, T.-W.; Polychronopoulou, K.; Choi, J.W.; Coskun, A. Chemical blowing approach for ultramicroporous carbon nitride frameworks and their applications in gas and energy storage. Adv. Funct. Mater. 2017, 27, 1604658. [CrossRef]

12. Titirici, M.-M.; White, R.J.; Brun, N.; Budarin, V.L.; Su, D.S.; del Monte, F.; Clark, J.H.; MacLachlan, M.J. Sustainable carbon materials. Chem. Soc. Rev. 2015, 44, 250-290. [CrossRef] [PubMed]

13. Benzigar, M.R.; Talapaneni, S.N.; Joseph, S.; Ramadass, K.; Singh, G.; Scaranto, J.; Ravon, U.; Al-Bahily, K.; Vinu, A. Recent advances in functionalized micro and mesoporous carbon materials: Synthesis and applications. Chem. Soc. Rev. 2018, 47, 2680-2721. [CrossRef] [PubMed]

14. Lee, Y.J.; Talapaneni, S.N.; Coskun, A. Chemically activated covalent triazine frameworks with enhanced textural properties for high capacity gas storage. ACS Appl. Mater. Interfaces 2017, 9, 30679-30685. [CrossRef] [PubMed]

15. Lee, J.; Kim, J.; Hyeon, T. Recent progress in the synthesis of porous carbon materials. Adv. Mater. 2006, 18, 2073-2094. [CrossRef]

16. Ouyang, H.; Gong, Q.; Li, C.; Huang, J.; Xu, Z. Porphyra derived hierarchical porous carbon with high graphitization for ultra-stable lithium-ion batteries. Mater. Lett. 2019, 235, 111-115. [CrossRef]

17. Sevilla, M.; Fuertes, A.B. Graphitic carbon nanostructures from cellulose. Chem. Phy. Lett. 2010, 490, 63-68. [CrossRef]

18. Yang, J.; Zuo, S. Facile synthesis of graphitic mesoporous carbon materials from sucrose. Diam. Relat. Mater. 2019, 95, 1-4. [CrossRef]

19. Wang, H.; Yi, H.; Zhu, C.; Wang, X.; Jin Fan, H. Functionalized highly porous graphitic carbon fibers for high-rate supercapacitive electrodes. Nano Energy 2015, 13, 658-669. [CrossRef] 
20. Selvamani, V.; Ravikumar, R.; Suryanarayanan, V.; Velayutham, D.; Gopukumar, S. Garlic peel derived high capacity hierarchical N-doped porous carbon anode for sodium/lithium ion cell. Electrochim. Acta 2016, 190, 337-345. [CrossRef]

21. Lim, D.G.; Kim, K.; Razdan, M.; Diaz, R.; Osswald, S.; Pol, V.G. Lithium storage in structurally tunable carbon anode derived from sustainable source. Carbon 2017, 121, 134-142. [CrossRef]

22. Wang, W.X.; Wan, Y.; Wu, S.F.; Li, M.C.; Cao, L.J.; Lv, F.C.; Yang, M.Y.; Sun, Z.F.; Sun, R.; Lu, Z.G. Graphitized porous carbon prepared from pyrolysis of Sterculia scaphigera and its application in lithium ion batteries. RSC Adv. 2015, 5, 46558-46563. [CrossRef]

23. Zhou, X.; Chen, F.; Bai, T.; Long, B.; Liao, Q.; Ren, Y.; Yang, J. Interconnected highly graphitic carbon nanosheets derived from wheat stalk as high performance anode materials for lithium ion batteries. Green Chem. 2016, 18, 2078-2088. [CrossRef]

24. Han, S.-W.; Jung, D.-W.; Jeong, J.-H.; Oh, E.-S. Effect of pyrolysis temperature on carbon obtained from green tea biomass for superior lithium ion battery anodes. Chem. Eng. J. 2014, 254, 597-604. [CrossRef]

25. Choi, C.; Seo, S.-D.; Kim, B.-K.; Kim, D.-W. Enhanced lithium storage in hierarchically porous carbon derived from waste tea leaves. Sci. Rep. 2016, 6, 39099. [CrossRef] [PubMed]

26. Sankar, S.; Ahmed, A.T.A.; Inamdar, A.I.; Im, H.; Im, Y.B.; Lee, Y.; Kim, D.Y.; Lee, S. Biomass-derived ultrathin mesoporous graphitic carbon nanoflakes as stable electrode material for high-performance supercapacitors. Mater. Des. 2019, 169, 107688. [CrossRef]

27. Peng, C.; Yan, X.-B.; Wang, R.-T.; Lang, J.-W.; Ou, Y.-J.; Xue, Q.-J. Promising activated carbons derived from waste tea-leaves and their application in high performance supercapacitors electrodes. Electrochim. Acta 2013, 87, 401-408. [CrossRef]

28. Sankar, S.; Saravanan, S.; Ahmed, A.T.A.; Inamdar, A.I.; Im, H.; Lee, S.; Kim, D.Y. Spherical activated-carbon nanoparticles derived from biomass green tea wastes for anode material of lithium-ion battery. Mater. Lett. 2019, 240, 189-192. [CrossRef]

29. Chen, M.; Yan, D.; Zhang, X.; Yu, Z.; Zhu, G.; Zhao, Y.; Lu, S.; Chen, G.; Xu, H.; Yu, A. Activated carbons by a hydrothermal-assisted activated method for Li-ion batteries. Mater. Lett. 2017, 196, 276-279. [CrossRef]

30. Wang, G.; Wang, D.; Kuang, S.; Xing, W.; Zhuo, S. Hierarchical porous carbon derived from rice husk as a low-cost counter electrode of dye-sensitized solar cells. Renew. Energy 2014, 63, 708-714. [CrossRef]

31. Sun, L.; Fu, Y.; Tian, C.; Yang, Y.; Wang, L.; Yin, J.; Ma, J.; Wang, R.; Fu, H. Isolated boron and nitrogen sites on porous graphitic carbon synthesized from nitrogen-containing chitosan for supercapacitors. Chem. Sus. Chem. 2014, 7, 1637-1646. [CrossRef] [PubMed]

32. Rajagopal, R.R.; Aravinda, L.S.; Rajarao, R.; Bhat, B.R.; Sahajwalla, V. Activated carbon derived from non-metallic printed circuit board waste for supercapacitor application. Electrochim. Acta 2016, 211, 488-498. [CrossRef]

33. Nagalakshmi, M.; Kalaiselvi, N. Mesoporous dominant cashewnut sheath derived bio-carbon anode for LIBs and SIBs. Electrochim. Acta 2019, 304, 175-183. [CrossRef]

34. Bazan, A.; Nowicki, P.; Półrolniczak, P.; Pietrzak, R. Thermal analysis of activated carbon obtained from residue after supercritical extraction of hops. J. Therm. Anal. Calorim. 2016, 125, 1199-1204. [CrossRef]

35. ALOthman, Z. A review: Fundamental aspects of silicate mesoporous materials. Materials 2012, 5, 2874. [CrossRef]

36. Sankar, S.; Lee, H.; Jung, H.; Kim, A.; Ahmed, A.T.A.; Inamdar, A.I.; Kim, H.; Lee, S.; Im, H.; Young Kim, D. Ultrathin graphene nanosheets derived from rice husks for sustainable supercapacitor electrodes. New J. Chem. 2017, 41, 13792-13797. [CrossRef]

37. Cui, J.; Xi, Y.; Chen, S.; Li, D.; She, X.; Sun, J.; Han, W.; Yang, D.; Guo, S. Prolifera-green-tide as sustainable source for carbonaceous aerogels with hierarchical pore to achieve multiple energy storage. Adv. Funct. Mater. 2016, 26, 8487-8495. [CrossRef]

38. Cui, J.; Cheng, F.; Lin, J.; Yang, J.; Jiang, K.; Wen, Z.; Sun, J. High surface area C/SiO2 composites from rice husks as a high-performance anode for lithium ion batteries. Powder Technol. 2017, 311, 1-8. [CrossRef]

39. Tang, J.; Etacheri, V.; Pol, V.G. Wild Fungus Derived carbon fibers and hybrids as anodes for lithium-ion batteries. ACS Sustain. Chem. Eng. 2016, 4, 2624-2631. [CrossRef]

40. Chen, S.; Yeoh, W.; Liu, Q.; Wang, G. Chemical-free synthesis of graphene-carbon nanotube hybrid materials for reversible lithium storage in lithium-ion batteries. Carbon 2012, 50, 4557-4565. [CrossRef] 
41. Qie, L.; Chen, W.-M.; Wang, Z.-H.; Shao, Q.-G.; Li, X.; Yuan, L.-X.; Hu, X.-L.; Zhang, W.-X.; Huang, Y.-H. Nitrogen-doped porous carbon nanofiber webs as anodes for lithium ion batteries with a superhigh capacity and rate capability. Adv. Mater. 2012, 24, 2047-2050. [CrossRef] [PubMed]

42. Mondal, A.K.; Kretschmer, K.; Zhao, Y.; Liu, H.; Fan, H.; Wang, G. Naturally nitrogen doped porous carbon derived from waste shrimp shells for high-performance lithium ion batteries and supercapacitors. Microporous Mesoporous Mater. 2017, 246, 72-80. [CrossRef]

43. Tao, L.; Zheng, Y.; Zhang, Y.; Ma, H.; Di, M.; Zheng, Z. Liquefied walnut shell-derived carbon nanofibrous mats as highly efficient anode materials for lithium ion batteries. RSC Adv. 2017, 7, 27113-27120. [CrossRef]

44. Lv, W.; Wen, F.; Xiang, J.; Zhao, J.; Li, L.; Wang, L.; Liu, Z.; Tian, Y. Peanut shell derived hard carbon as ultralong cycling anodes for lithium and sodium batteries. Electrochim. Acta 2015, 176, 533-541. [CrossRef]

45. Fey, G.T.-K.; Chen, K.-L.; Chang, Y.-C. Effects of surface modification on the electrochemical performance of pyrolyzed sugar carbons as anode materials for lithium-ion batteries. Mater. Chem. Phy. 2002, 76, 1-6. [CrossRef]

46. Arrebola, J.C.; Caballero, A.; Hernán, L.; Morales, J.; Olivares-Marín, M.; Gómez-Serrano, V. Improving the performance of biomass-derived carbons in li-ion batteries by controlling the lithium insertion process. J. Electrochem. Soc. 2010, 157, A791-A797. [CrossRef]

47. Xiang, J.; Lv, W.; Mu, C.; Zhao, J.; Wang, B. Activated hard carbon from orange peel for lithium/sodium ion battery anode with long cycle life. J. Alloys Compd. 2017, 701, 870-874. [CrossRef]

48. Fromm, O.; Heckmann, A.; Rodehorst, U.C.; Frerichs, J.; Becker, D.; Winter, M.; Placke, T. Carbons from biomass precursors as anode materials for lithium ion batteries: New insights into carbonization and graphitization behavior and into their correlation to electrochemical performance. Carbon 2018, 128, 147-163. [CrossRef]

49. Luna-Lama, F.; Rodríguez-Padrón, D.; Puente-Santiago, A.R.; Muñoz-Batista, M.J.; Caballero, A.; Balu, A.M.; Romero, A.A.; Luque, R. Non-porous carbonaceous materials derived from coffee waste grounds as highly sustainable anodes for lithium-ion batteries. J. Clean. Prod. 2019, 207, 411-417. [CrossRef]

50. Wu , X.-L.; Chen, L.-L.; Xin, S.; Yin, Y.-X.; Guo, Y.-G.; Kong, Q.-S.; Xia, Y.-Z. Preparation and li storage properties of hierarchical porous carbon fibers derived from alginic acid. ChemSusChem 2010, 3, 703-707. [CrossRef]

51. Caballero, A.; Hernán, L.; Morales, J. Limitations of Disordered Carbons Obtained from Biomass as Anodes for Real Lithium-Ion Batteries. ChemSusChem 2011, 4, 658-663. [CrossRef] [PubMed]

52. Zhang, C.; Kong, R.; Wang, X.; Xu, Y.; Wang, F.; Ren, W.; Wang, Y.; Su, F.; Jiang, J.-X. Porous carbons derived from hypercrosslinked porous polymers for gas adsorption and energy storage. Carbon 2017, 114, 608-618. [CrossRef]

(C) 2019 by the authors. Licensee MDPI, Basel, Switzerland. This article is an open access article distributed under the terms and conditions of the Creative Commons Attribution (CC BY) license (http://creativecommons.org/licenses/by/4.0/). 